\title{
The fable of the pine and the palm tree: the two extremes. Strategies to maximize the placebo effect and minimize the nocebo effect in primary health care
}

\author{
José Luis Turabián*, and Sandra Moreno-Ruiz \\ Specialists in Family Medicine and Community, Health Center "Santa Maria de Benquerencia”. Calderón de la Barca, 24. 45313 Yepes, Toledo, Spain
}

\begin{abstract}
The concepts of placebo and nocebo are important in medicine, especially in family medicine and mental health. Similarly, the prescription of drugs for treatment is a common medical response to the patient's query, but many of them have adverse drug reactions of non-pharmacological origin. These concepts can be difficult to explain and understand. These characteristics are presented based on a fable. The fable is an adult education method which can serve to intuitively understand abstract concepts, by linking them to specific Situations, and so to facilitate Their assimilation. Patients treated at Primary Health Care have emotional characteristics and personality traits, whose knowledge may allow identifying which of them, will have a placebo response and which of them a nocebo response in relation to prescription drugs. Furthermore, the presence of multidrug adverse reactions in the patient is an indicator that suggests the existence of emotional characteristics (anxiety and depression), negative personality traits, or contextual psychosocial problems. The moral of the fable is that the family doctor should know the characteristics of their patients to maximize the placebo effect and minimize the nocebo, and investigate the emotional and contextual problematic in cases of patients with nocebo effects.
\end{abstract}

\section{Introduction}

Primary health care provides the first point of entry for healthcare delivery, with links to higher levels of the health system and other services. Family physicians do not treat diseases but take care of people. They need to understand that the disease process is socially constructed within the patient's life, and they have to mediate between the subjective experience of illness of the patient and scientific explanation. But, these concepts can be difficult to understand and explain, even for experienced physicians in the specialty, and in other medical areas. Therefore, it is necessary to achieve a more meaningful representation of the fundamental concepts of Family Medicine, and facilitate the transfer of these concepts to clinical practice [1].

One of these difficult concepts is placebo effects. These are often considered the effects of an "inert substance," but that characterization is misleading. In a broad sense, placebo effects are improvements in patients' symptoms that are attributable to their participation in the therapeutic encounter, with its rituals, symbols, and interactions. The placebo effect can be observed in any medical encounter and not solely in clinical trials that incorporate a placebo treatment group. It is possible that the provision of any therapeutic regimen will elicit a placebo effect [2].

Placebo effects rely on complex neurobiologic mechanisms involving neurotransmitters and activation of specific, quantifiable, and relevant areas of the brain. Many common medications also act through these pathways. In addition, genetic signatures of patients who are likely to respond to placebos are beginning to be identified. The psychosocial factors that promote therapeutic placebo effects also have the potential to cause adverse consequences, known as nocebo effects. Not infrequently, patients perceive side effects of medications that are actually caused by anticipation of negative effects or heightened attentiveness to normal background discomforts of daily life in the context of a new therapeutic regimen. Unfortunately, much of what is known about placebo effects has been discovered through laboratory experiments with healthy volunteers, employing deceptive techniques that are not directly pertinent to clinical practice. We need more research involving clinical interventions [3].

A strong placebo response in psychiatric disorders has been noted for the past 50 years, but the predictors of the placebo response are still to be discovered [4].

In this context, it would be important, especially for the family doctor, to having some method or strategy that would allow to he or she predict the placebo and nocebo effects, to increase the effect in the first, and minimize problems in the seconds. To mostarlo, with an educational approach, we use a short fable.

The fable is an adult education method that can serve to intuitively understand abstract concepts, by linking them to specific situations, and so to facilitate their assimilation. The fable is a brief written narrative that has a didactic purpose; this means that there is a moral or teaching, and it applies to our life. Most of his characters are animals, but also plants, etc., that think and speak like they were human beings. In the fable you can distinguish two parts: one is the story itself; and the other moral.

Correspondence to: José Luis Turabián, Specialists in Family Medicine and Community, Health Center "Santa Maria de Benquerencia". Calderón de la Barca, 24. 45313 Yepes,Toledo, Spain, Tel: +98 218490254; E-mail: jturabianf@hotmail.com

Key words: adverse drug reaction, family practice, medical education, mental health, physician-patient relations, placebo effect

Received: August 09, 2016; Accepted: August 24, 2016; Published: August 27, 2016 


\section{Case report: the fable of the pine and the palm tree}

Once upon a time, a pine tree and a palm tree who consulted to the doctor.

Mr. Pine Tree was a narrow, conical tree, with gray and smooth bark, and cracked with age, of $30 \mathrm{~m}$ high, with its aromatic leaves in form of needle and green and brown colour. He was a cheerful, positive and optimistic patient, who faces life with hope and energy, and with the ability to recover from the adversity, with a direct and unselfish temperament, which reflected enthusiasm for the arrival of new illusions and achieving new goals.

- "I come by this wound in my bark, Doctor," said the Mr. Pine to the doctor.

- "Aha, I see ... I will prescribe this treatment: it is one tablet every 6 hours, and this cream ...", said the doctor.

\section{After one week, Mr. Pine Tree returned to the office:}

-"Doctor, I finished treatment, which worked very well to me, and I'm better ... The treatment was a success".

Another day consulted Mrs. Palm Tree, with its thick fibrous trunk and big green leaves at the end of the stem, of $15 \mathrm{~m}$ high. She was angry, hostile, and anxious.

- "Doctor, I have dark spots on the leaves! I am very concerned. I know a palm tree that did the same ... and ended up in the hospital. You have to do something ", said Mrs. Palm Tree distressed, as he began to mourn.

- "Hmmm ... I see. I am going to prescribe this treatment: one tablet every 6 hours and this cream ", said the doctor.

After a few days Mrs. Palm Tree returned to the medical office:

- "The tablets worsen stains ... Now the spots on the leaves are already black .. ¡Got to do something, Doctor!. Please, send me further treatment ", said with anxiety and tears.

After a few weeks Mrs. Palm Tree returned to the office:

- ¡ The last tablets sat me too bad! Now the spots on the leaves have a light green halo, and sometimes acquire a brown tone ... ii You have to provide me other treatment!! ", demanded angrily.

After a few weeks Mrs. Palm Tree returned again to the office:

-"These tablets a selective inhibitor of serotonin reuptake that you provided have not worked, and I feel very bad! The spots have become transparent, but the blade is weak...”.

The doctor thought:
"The pine tree is the sea and sky and mountains. The palm tree is dryness of misfortune with broken branches; is the disease of the loneliness, thirst and the remoteness on the desert, seeking, with anxiety of a dream, a source in cold water in an arid field".

“To Mr. Pine Tree everything seems to sit well to him. He has beneficial effects produced by his positive expectations: he is a placebo effect. By contrast, to the Mrs. Palm Tree all drugs sit badly to her, including antidepressants. She is a nocebo effect".

\section{Discussion: the moral of the fable}

The placebo can be defined as a beneficial effect produced by positive expectations, and this are related with personality traits such as the ability to recover from adversity, direct temperament, and altruism, that are positive predictors of placebo effect. The reverse of the placebo effect is the nocebo: the personality traits of anger and hostility, anxiety and depression are predictors factors [5]. So, patients' expectations, and personality traits are important determinants of unwanted adverse effects, and clinicians must have strategies to foster optimal treatment outcomes [6].

There has been a long standing debate on the placebo effect in pharmacotherapy of depression especially in patients with mild to moderate forms of the illness. And these clinical implications of placebo are more important compared with the differences in efficacy between antidepressants [7]. The current research demonstrates that in patients who develop a medication response conditioned to a "placebo" and who are then given the placebo plus a medication dose too low by itself to alter physiology, the established association can be reinforced, thus producing a physiologic effect [8].

According of this, it has been proposed various strategies to maximize placebo effect and minimize nocebo effect [6]. The measures an individual's ability to recover from adversity and the ability to withstand and overcome stressors and difficult situations, could allow predict people who show the greatest ability to take environmental information (the placebo) and make it a change in the biology. This strategy is of great importance in medical clinical work, especially in primary care, and in relation for prescription drugs so that they show a positive effect on patients.

But in primary care, where the family physician in his work continuing care with the patient comes to know the personality traits of their patients, and can know at a given patient if it is an anxious person (people that perceive situations as dangerous or threatening, cautious people, tense, easily fatigable, timid, apprehensive, pessimistic, etc.) [9], or if the patient is a person with depressive personality (individuals that are characterized by particularly serious show, unable to have fun or relax and humourless, with negative thoughts, pessimistic, etc.;

Table 1. Types of patients, based on the knowledge acquired by the family doctor during continuity of care, as an aid to decision-making in the use of drugs.

\begin{tabular}{|l|l|l|}
\hline Types of patients & Predictors factors & Action to be taken by the family doctor \\
\hline $\begin{array}{l}\text { Patients with positive effects on drug use ("Patients } \\
\text { Placebo") }\end{array}$ & $\begin{array}{l}\text {-Personality traits: positive expectations, the ability to } \\
\text { recover from adversity, direct temperament, and altruism } \\
\text {-Absence of anxiety / depression }\end{array}$ & $\begin{array}{l}\text {-Reinforcing the positive expectations of the patient by the } \\
\text { physician (the drug is the doctor) }\end{array}$ \\
\hline $\begin{array}{l}\text { Patients with negative effects on the use of drugs ("Patients } \\
\text { Nocebo") }\end{array}$ & $\begin{array}{l}\text {-Personality traits: } \\
\text { anger and hostility, } \\
\text {-Emotional problems (anxiety / depression) }\end{array}$ & $\begin{array}{l}\text {-Avoid the compulsive use of drugs } \\
- \text { Counterpose the negative expectations of the patient with } \\
\text { the expression of the positive effects from the doctor (the } \\
\text { drug is the doctor) } \\
\text {-Avoid transfer, by de doctor to the patient, the expectations } \\
\text { of doubt or of alarm of possible adverse drug effects. } \\
\text {-Work on a biopsychosocial framework rather than } \\
\text { biomedical only }\end{array}$ \\
\hline $\begin{array}{l}\text {-Individuals that are characterized by particularly serious } \\
\text { show, unable to have fun or relax and humourless, with } \\
\text { negative thoughts, pessimistic, etc.; even without there } \\
\text { being an identifiable mental illness such as anxiety and / or } \\
\text { depression) }\end{array}$
\end{tabular}


Turabián JL (2016) The fable of the pine and the palm tree: the two extremes. Strategies to maximize the placebo effect and minimize the nocebo effect in primary health care

Table 2. key points useful as indicators of psychosocial or contextual problems (indicators that should alert to the physician).

\begin{tabular}{|l|}
\hline -Multiple Adverse Drug Reactions as an Indicator of Anxiety-Depression \\
\hline -Frequently consultations for minor problems \\
\hline -Frequently consultations with the same symptom or multiple queries in visits \\
\hline -Inquiries by symptoms that have been present for a long time previously \\
\hline -Inquiries by a chronic disease that seems to have changed \\
\hline -Inconsistency between the distress of the patient and the comparatively minor nature of the symptoms \\
\hline -Failure on the recovery time expected after an illness, accident or surgery \\
\hline -Frequents visits of parent with a child with minor problems (the child as a representative of disease in parents) \\
\hline -An adult patient with a family companion in the medical consultation \\
\hline -Trouble of making sense of the reason for consultation \\
\hline
\end{tabular}

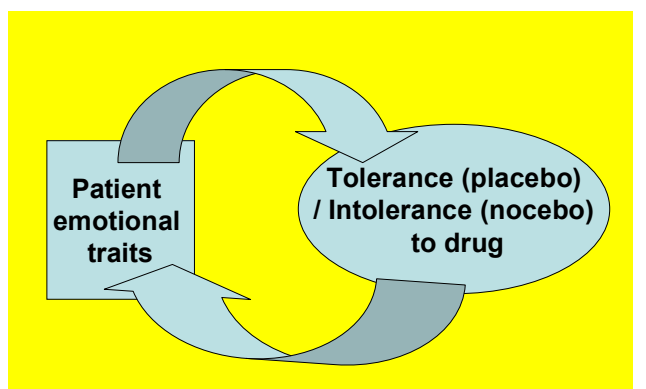

Figure 1. Cycle of emotional traits and tolerance/intolerance to drugs.

even without there being an identifiable mental illness such as anxiety and/or depression), and in consequence he or she could predict the useful response to the patient of a drug, and on the other end their drug intolerance. This cataloguing of patients in primary care is of great importance for therapeutic decision making (Table 1) [10].

On the other hand, if the patient personality traits can predict the usefulness of a drug in this patient, in the same way, you can follow that path in the opposite direction: multiple drug intolerance indicates emotional problems (anxiety/depression) in that patient [11] (Figure 1). The problem of drug prescription is one of the greatest social relevance in all countries, and adverse drug reactions are an important part of that problem, still common in clinical practice [12]. The communication of the patients of an adverse drugs reaction, which are not a direct result of the pharmacological action of the drug, is a common and costly phenomenon [13]. So, this adverse drug reaction to the drug is associated with the presence of anxiety or depression in these people (the patients with adverse drug reactions have a higher prevalence of emotional disturbances [12]. Thus, the presence of multiple adverse drug reactions in a patient in primary health care, is indicative of anxiety-depression, and constitute, together with other indicators, a signal of potential psychosocial problems or problems in the patient context, (Table 2) $[14,15]$.

In conclusion and summary (the moral of the fable) the family doctor should know the characteristics of their patients to maximize the placebo effect and minimize the nocebo, and investigate the emotional and contextual problematic in cases of patients with nocebo effects.

\section{References}

1. Turabian JL, Perez-Franco B (2016) The Family Doctors: Images and Metaphors of the Family Doctor to Learn Family Medicine. New York. Nova Publishers.

2. Sedgwick P (2011) The placebo effect. BMJ 343: d7665.

3. Kaptchuk TJ, Miller FG(2015) Placebo Effects in Medicine. N Engl J Med 373: 8-9

4. Weimer K, Colloca L, Enck P (2015) Placebo effects in psychiatry: mediators and moderators. Lancet Psychiatry 2: 246-257.

5. Peciña M, Azhar H, Love TM, Lu T, Fredrickson BL, et al. (2013) Personality Trait Predictors of Placebo Analgesia and Neurobiological Correlates. Neuropsychopharmacology 38: 639-646.

6. Bingel U(2014) For the Placebo Competence Team. Avoiding nocebo effects to optimize treatment outcome. JAMA 312: 693-694.

7. D'Souza U (2014) Mood disorders: Exploring the placebo effect, improving treatment and the promise of pharmacogenetics. OnMedicine. Blog Network. BioMed Central 25.

8. Albring A, Wendt L, Benson S, Nissen S, Yavuz Z, et al. (2014) Preserving Learned Immunosuppressive Placebo Response: Perspectives for Clinical Application. Clin Pharmacol Ther 96: 247-255.

9. Clark LA, Watson D, Mineka S (1994) Temperament, personality, and the mood and anxiety disorders. J Abnorm Psychol 103: 103-106.

10. the patient: interactions in general practice consultations. London: Tavistock Publications.

11. Gutiérrez-Islas E, Báez-Montiel BB, Turabián JL, Bolañnos-Maldonadoa M, HerreraOntañón JR, et al. (2012) Patients with adverse drug reactions have a higher prevalence of emotional disorders. Aten Primaria 44: 720-726.

12. Barsky AJ, Saintfort R, Rogers MP, Borus JF (2002) Nonspecific medication side effects and the nocebo phenomenon. JAMA 287: 622-627.

13. Turabian JL, Pérez Franco B (2011) Non-pharmacological aspects of medications Semergen 37: 246-251.

14. Stewart M, Brown JB, Weston WW, McWhinney IR, McWilliam CL, et al. (1995) Patient-centered medicine. Transforming the clinical method. London: SAGE Publications.

15. Turabian JL, Minier-Rodriguez LE, Cucho-Jove R, Rodriguez-Almonte FE, VillarinCastro A, et al. (2016) The Patient Companion in the Consultation of Family Medical Practice is an Indicator of Hidden Family Problems. Scientific Pages Fam Med 1: 001.

Copyright: $@ 2016$ Turabián JL. This is an open-access article distributed under the terms of the Creative Commons Attribution License, which permits unrestricted use, distribution, and reproduction in any medium, provided the original author and source are credited. 